Cuad. invest. hist. Brocar n. 16 (1990). Págs. 145-159.

\title{
LA MURALLA DE LOGROÑO: EXCAVACIONES ARQUEOLÓGICAS EN LA CALLE DEL NORTE
}

\author{
Pedro Alvarez Clavijo \\ Javier Ceniceros Herreros \\ José Antonio Tirado Martínez \\ Juan Manuel Tudanca Casero
}

\begin{abstract}
RESUMEN.- Memoria de la excavación de urgencia practicada en el casco antiguo de Logroño en Mayo de 1990. En ella pudo comprobarse la evolución del sistema defensivo de la ciudad desde época medieval combinando intenciones poliorcéticas con otras de ingeniería civil.

SUMMARY.-Memory of the urgent excavation effectuated in the old center of Logroño in May of 1990. Thanks to these works, it has been possible to get important information on the evolution of the defensive sistem of the town from the medieval period, evolution in which poliorcetical intentions are combined with civil engeneering works.
\end{abstract}

Palabras clave: Arqueología del Valle del Ebro, poliorcética medieval y moderna, arqueología industrial.

Los trabajos arqueológicos se llevaron a cabo entre mayo y junio de 1990 en la calle del Norte; en el solar liberado tras el derribo de las instalaciones industriales adosadas a la cabecera de la Iglesia de Santiago.

\section{ANTECEDENTES}

Durante los últimos años se vienen realizando en el casco antiguo logroñés numerosos trabajos de acondicionamiento y rehabilitación. Entre ellos destacan por su envergadura la construcción del llamado Parque del Ebro y la urbanización del entorno de la Iglesia de Santiago. Estas actuaciones implican la alteración en profundidad del subsuelo urbano como consecuencia de la remoción de tierras, destrucción de estructuras preexistentes, cimentación de nuevos edificios, canalizaciones, etc. 
Su realización no ha contado hasta ahora con supervisión arqueológica alguna, lo que ha ocasionado la destrucción total de los niveles arqueológicos allí dispuestos, así como la pérdida irreparable de cuantiosa información referida a la evolución históri ca de la ciudad de Logroño.

En el caso concreto que nos ocupa, la existencia de estructuras monumentales se contemplaba ya en el proyecto asumido por el Ayuntamiento. Fueron sin embargo las primeras obras de explanación, y no la investigación arqueológica previa, las que sacaron a la luz los restos de estructuras defensivas.

Después de dos meses de paralización de las obras se decidió por parte del Concejo logroñés la realización de un informe histórico artístico de los mismos. Por esta razón se solicitó nuestro concurso para llevar a cabo una actuación arqueológica de urgencia en la zona.

\section{DESARROLLO DE LA ACTUACIÓN}

El solar se encontraba parcialmente colmatado por escombros, procedentes de las estructuras superpuestas, y basuras acumuladas durante la realización de las obras. Todo ello había provocado el enmascaramiento de los restos. Los primeros trabajos se encaminaron por tanto a la limpieza del solar, necesaria para planificar una actuación en profundidad. Como resultado de la misma se pudo comprobar la alteración de las estructuras y de los niveles arqueológicos provocada por los medios mecánicos empleados.

Los trabajos arqueológicos se centraron en la delimitación de los elementos arquitectónicos parcialmente exhumados, en la búsqueda de otras estructuras relacionadas con ellos, y en el control de los estratos que documentarán las sucesivas ocupaciones del espacio.

Para la realización de la excavación se siguieron los criterios habituales en cualquier actuación sistemática. Partiendo de la elaboración de una planimetría general se realizó el necesario control de tallas y la obligada documentación gráfica de las evidencias. Todos los planos tienen como referencia el Plano Cero situado en la cota 378,80 señalada en le proyecto de remodelación.

\section{DESCRIPCIÓN DE LAS EVIDENCIAS}

\section{Estruciuras arquitectónicas}

Los restos arquitectónicos aparecidos durante la excavación los hemos subdividido en tres partes bien diferenciadas que describimos a continuación.

1. Lienzo (PLANO N. 2). Se trata de un muro adosado a la roca natural, orientado en paralelo al eje longitudinal de la Iglesia de Santiago de $17,50 \mathrm{~m}$. de longitud y una altura máxima de $3,80 \mathrm{~m}$.

Formando parte del mismo es posible desglosar los siguientes elementos:

-Contrafuerte escalonado adosado al lienzo. Mide 2,10 m. de anchura, con una disposición no uniforme. (PLANO N. 3 ). 
-Zócalo escalonado en la base del lienzo de $0,70 \mathrm{~m}$. de altura; sólo conservado en algunas zonas de la totalidad del trazado.

Los materiales empleados en su construcción alternan sillares, mampuesto, ladrillo y argamasa en todos sus elementos, pudiendo observar una mayor regularidad en la composición del contrafuerte.

La presencia de ladrillos y mampostería puede ser fruto de intervenciones posteriores, presuponiendo una estructura original fundamentada en sillares bien labrados con relleno fraguado con argamasa.

El muro presenta numerosas alteraciones posteriores a su construcción, producto tanto de la acción de los elementos naturales como de la acción humana. Unas y otras son de difícil precisión cronológica y funcional.

-Derrumbe de parte de su trazado por la propia presión del terreno.

-Filtraciones de la capa freática en la base del lienzo que completan los desperfectos anteriores.

-Entre las alteraciones intencionadas se aprecia el aprovechamiento de los muros para el soporte de instalaciones industriales, provocando su desaparición en algunos sectores, y la inclusión de materiales constructivos modernos (PLANO N.․ 2).

2. Baluarte (PLANO N. 1). Con esta denominación nos referimos a una estructura que presenta dos tramos, el primero, que arranca de la roca natural en dirección $\mathrm{N}$., de $2 \mathrm{~m}$. de longitud y un segundo de $7 \mathrm{~m}$. de orientación SE-NO (PLANO N.․ 1).

En el límite del área de nuestra actuación el muro flexiona cambiando de dirección, lo cual permite suponer su continuidad en dirección E-O (PLANO N.․1).

En la parte exterior alcanza una altura máxima de 3,80 m. mientras que en la interior no supera los $2 \mathrm{~m}$. Esta diferencia se debe al aprovechamiento del declive del terreno para su construcción.

Los materiales empleados no son homogéneos en toda la construcción. En ella podemos distinguir una estructura de manera tripartita:

-Cara exterior: (PLANO N. 4). Está formada por 5 hiladas escalonadas a las que se superponen otras 9 formando un talud, rematado por otra hilera perfectamente vertical que posiblemente continuaría con otras hiladas en $n .{ }^{\mathrm{o}}$ difícil de determinar. Todo el baluarte quedaría reforzado al rellenar su interior.

Las hiladas las forman sillares escuadrados con dimensiones variadas, homogéneamente dispuestos en hileras de entre 25 y $35 \mathrm{~cm}$. de grosor, formando un talud escalonado en la base y liso en la zona superior. Los sillares, colocados a mata junta, han sido perfectamente alisados en su cara externa, rellenando minuciomente con argamasa sus intersticios. En las primeras hiladas se aprecian algunas perforaciones realizadas para favorecer el drenaje del terreno y evitar el derrumbe.

Relleno (PLANO N. 6). Compuesto por cascotes y cantos rodados trabados con argamasa muy compacta.

Cara interna. Formada por sillarejo muy irregular cimentado por cantos rodados de pequeño tamaño y capas de arcilla (PLANO N.. 5).

Reforzando el cimiento en el ángulo entre los dos tramos del baluarte aparece una hilera más de sillarejo, adelantada con respecto al resto de las hiladas.

$\mathrm{Al}$ contrario que en la cara externa, ésta no está regularizada, y los intersticios del sillarejo no han sido rellenados con argamasa de ningún tipo. El afinamiento interno no es necesario debido a que el espacio interno del baluarte fue rellenado con tierra. 
En líneas generales se puede constatar una mejor conservación con respecto al lienzo, debido sin duda a la mejor calidad del aparejo, a la menor presión ejercida por el terreno y a menores alteraciones posteriores.

No obstante se observan una serie de irregularidades:

-Huellas de posibles impactos.

-Modificaciones sufridas por el reaprovechamiento de la estructura.

Una vez perdida la funcionalidad defensiva del bastión, el espacio extramuros fue utilizado para la instalación de nuevas construcciones.

Hay que señalar la eliminación de 5 hiladas del talud que fueron rebajadas a pi co para obtener una pared vertical integrada en un edificio de cuya techumbre se aprecian los puntos de apoyo en la $11^{\mathrm{a}}$ hilada.

-Otras modificaciones.

En un momento reciente, cuando se urbanizó la Calle del Norte, el punto de flexión del bastión fue cortado por dos zanjas que sirvieron para la instalación del desagüe de la zona y de una conducción de agua potable. Estas obras tan sólo alteraron las hiladas superiores.

3. Otros elementos constructivos (PLANO N.7). En la base del baluarte, sobre la primera hilada de sillares, aparecen los restos de un empedrado de cantos rodados fraguados con calicanto. Su funcionalidad como probable camino de ronda no pudo ser comprobada debido a las limitaciones del área excavada. Sí fue posible constatar que no se extendía hasta el lienzo, bien porque nunca llegó hasta él, bien por haber sido destruido.

En la zona exterior del lienzo encontramos parte de un pavimento compuesto por lajas planas de piedra y ladrillos que incluye un canal de drenaje adosado al zócalo. Este canal presenta una base de ladrillo, material que combinado con lajas se emplea también en los laterales ofreciendo una cubierta de lajas integradas en el conjunto. Este elemento responde sin duda a la necesidad de sanear el espacio extramuros encauzando el agua que filtra del terreno.

El conjunto de las estructuras arquitectónicas fue reaprovechado para el asentamiento de instalaciones industriales. Se procedió para ello al reforzamiento con hormigón y entramados de madera de las zonas deterioradas del muro. De estas instalaciones se aprecian los restos de dos depósitos y de varias cubetas de decantación, comunicadas entre si, que fueron a su vez cubiertas en una fase posterior. Uno de los depósitos se superpone y anula la canalización existente en la base del lienzo a la que nos hemos referido anteriormente.

\section{Materiales muebles}

Los materiales muebles aparecidos durante la excavación se componen básicamente de cerámica, algún fragmento de metal o vidrio y diversos elementos constructivos.

Todos ellos han aparecido fuera de su contexto estratigráfico, en escombreras que recogen materiales de diversas épocas. Sólo los correspondientes al relleno del interior del baluarte podian haber proporcionado datos de interés, pero desafortuandamente fueron alterados antes de la excavación. 
De todos los materiales es la cerámica el más significativo. Hay que destacar la presencia en el interior del baluarte de cuatro fragmentos de cerámica prehistórica, rodados y sin contexto. Se trata de cerámica moldeada a mano, no torneada de superficies tanto espatuladas como alisadas y cocción básicamente reductora. Estos escasos vestigios no permiten definir ninguna forma concreta, pero sus caracteres técnicos nos indican su correspondencia al Bronce Final o I Edad del Hierro.

También se documenta un fragmento de cerámica celtibérica, realizado a torno, con restos de decoración pintada. La adscripción cultural es indudable para todos ellos, sin que puedan confundirse con otras cerámicas de épocas históricas. Su valoración será planteada más adelante.

El resto del conjunto cerámico lo componen vasijas elaboradas a torno de coloraciones diversas, desde negras a rojas o naranjas, algunas con superficies vidriadas. Corresponden a formas y cronologias diferentes, relacionadas con el desarrollo de la ciudad hasta la actualidad.

\section{INTERPRETACIÓN DE LAS EVIDENCIAS}

Del análisis de las estructuras y de los materiales descubiertos se desprenden una serie de consideraciones que permiten avanzar una interpretación del conjunto, realizada desde un punto de vista arqueológico, sin perjuicio de que en otrolugar se vean complementadas con el estudio de la documentación recogida en los archivos de la ciudad'.

Ante todo, es preciso realizar una breve referencia a las características del terreno, que en su aspecto actual dista mucho de ser el que, a lo largo de la historia de la Ciudad, ha venido condicionando su desarrollo urbanístico.

El elemento que en mayor medida contribuyó a alterar la fisonomía del sector septentrional del Casco Antiguo fue, sin duda la apertura de la calle Sagasta y la construcción del Puente de Hierro, obras ambas realizadas a finales del s. XIX.

A partir de entonces se perdió la perspectiva que, desde el Sotillo, permita apreciar el importante desnivel salvado por las alineaciones exteriores del caserio, que descendían desde la Rua-Vieja hasta el Camino de San Gregorio, asi como la potencia del edificio de la Iglesia de Santiago, que quedaba mucho más realzada desde el antiguo punto de vista.

Tanto las nuevas estructuras como la paulatina colmatación del área urbana, han contribuido a matizar los desniveles originales. Sin embargo, tras la intervención en el solar estudiado, contamos con algunos datos más referidos a esta adaptación de las construcciones a las características del terreno.

La Iglesia de Santiago destacaba sobre el entorno no sólo debido al volumen del edificio sino también como consecuencia de encontrarse situada sobre un promontorio de arcillas y areniscas, cuyos estratos quedaron perfectamente visibles tras la limpieza del relleno del baluarte, que presenta un importante declive tanto hacia el Ebro, como hacia el callejón de San Pablo. La existencia de este escalón, que permite aflorar a los

1 Consúltese en este mismo volumen el trabajo de B. ARRUE y E. MARTINEZ GLERA. 
diferentes acuiferos que surcan el subsuelo de Logroño y que, entre otras, surtían a la Fuente de los Peregrinos, condicionará la construcción de las sucesivas estructuras localizadas junto a la Iglesia de Santiago.

A partir de la información recogida, podemos relacionar las citadas estructuras y los restos muebles recuperados, con la existencia de varias fases en la ocupación del espacio analizado, que podrían agruparse en tres apartados:

-Evidencias muebles de ocupaciones protohistóricas.

-Estructuras defensivas modernas y, quizás, en parte medievales.

-Reutilizaciones modernas y contemporáneas para la instalación de talleres artesanales e industrias.

\section{Evidencias protohistoricas}

La existencia de un promontorio de arcillas y areniscas que dominaba el cauce del Ebro, quedando a salvo de sus avenidas y permitiendo, a la vez, acceder fácilmente a unos importantes recursos de agua y tal vez de pesca, pudo propiciar la elección de este lugar para el asentamiento de un habitat prerromano.

Esta posibilidad aparece avalada por evidencias, hasta el momento, escasas pero significativas. Se trata, de cuatro fragmentos de cerámica no torneada que, por sus características técnicas nos remiten a algún momento del Bronce Final o la Primera Edad del Hierro. Vienen a ser, por tanto, los restos más antiguos descubiertos hasta ahora en el casco urbano logroñés, y cuentan con los paralelos más cercanos en los yacimientos de La Coronilla (Lardero) y La Custodia (Viana) ${ }^{2}$.

Junto a ellos, un fragmento de cerámica celtibérica, con restos de una franja de la característica decoración pintada, pondría de manifiesto la existencia, durante los últimos siglos antes del cambio de era, de alguna actividad humana, que encuentra adecuada réplica en la orilla opuesta del Ebro, tal como se deduce de las excavaciones realizadas en el Monte Cantabria ${ }^{3}$.

El hecho de que estas cerámicas aparecieran en el relleno del bastión-baluarte, al pie del escarpe de roca natural, permite suponer que habrían sido acarreadas desde la cima del promontorio sobre el que se asienta la Iglesia de Santiago, que bien pudo haber sido el solar de estas hipotéticas ocupaciones protohistóricas.

\section{Estructuras defensivas}

Los restos de mayor entidad, descritos en el apartado anterior como lienzo y baluarte/bastión, se relacionan con el antiguo cinturón amurallado de la Ciudad.

2 J. M. RODANES; M. P. GALVE (1982): "El yacimiento con cerámica excisa de la Coronilla (Lardero, La Rioja)". Bajo Aragón. Prehistoria, IV. Caspe. Pp.: 84-95. A. CASTIELLA (1975): "Estratigrafía en el poblado de la Edad del Hierro de La Custodia (Viana, Navarra)". Noticiario Arqueológico Hispanico, Prehistoria, 4. Madrid. Pp.: 199-227.

3 C. L. PEREZ ARRONDO (1979): “Excavaciones arqueológicas en el Monte Cantabria (Logroño). Campaña de 1977. Informe preliminar”. Cuadernos de Investigación. Geografia e Historia, tomo V.1. Logroño. Pp.: 65-77. 
Ateniéndonos a su disposición, todo parece indicar una mayor antigüedad del lienzo con respecto al baluarte. Las diferencias se extienden a otros aspectos como la morfología de una y otra obra, el tipo de aparejo empleado $y$, posiblemente, la funcionalidad concreta que dió origen a cada una de ellas.

Por lo que respecta al lienzo, el hecho de que carezca de continuidad en el espacio delimitado por el baluarte, permite apuntar la hipótesis de que en ese punto fuera innecesaria la contención del terreno, ante la afloración del escarpe de arenisca. Contrariamente, a medida que nos acercamos a la calle de San Pablo, el relieve presenta un acusado declive que, en su momento obligaría a realizar obras de contención que asegurasen mediante un encintado de sillería, el mantenimiento de la terraza sobre la que se sucedieron las reedificaciones de la Iglesia de Santiago. Habida cuenta de que nuestra actuación debió circunscribirse al solar liberado, no pudimos comprobar si dicho encintado sufría algún cambio de trayectoria al llegar a la citada calle de San Pablo, lo que hubiera permitido contrastar esta suposición. Por idéntica circunstancia no es posible saber si el contrafuerte escalonado que se adosa al lienzo es un elemento puntual o si responde a un criterio constructivo general y, por lo tanto, se repetiria en otros puntos de la estructura. Por lo que respecta al zócalo existente al pie del lienzo, su construcción se haría necesaria ante la presión ejercida por el terreno sobre aquél, propiciada por las constantes filtraciones de la capa freática. Circunstancialmente, esta estructura pudo ser útil como un elemento defensivo más, tanto frente a avatares bélicos como frente a las eventuales avenidas del Ebro.

La función defensiva parece estar mucho más clara en el origen del baluarte, que ya no se construye adosado al terreno sino exento, con la clara intención de crear una glorieta avanzada respecto a la mole de la Iglesia, sobre la cuál poder emplazar piezas de artillería. El talud que presenta su cara externa no hace sino confirmar esta impresión. Por lo que respecta al relleno del interior del bastión, en caso de no haberse visto alterado, tal vez hubiera aportado algún dato en torno a la fecha de su realización.

Aunque los trabajos tampoco tuvieron continuidad en la zona occidental, el quiebro que sufre la dirección del muro sugiere que continuaría paralelo a la calle del Norte hasta enlazar con el cubo del Revellín.

Los restos descubiertos en las bodegas de algunas casas de la C/Barriocepo, singularmente, la del edificio actualmente ocupado por el Colegio de Arquitectos, permiten confirmar esta hipótesis. A diferencia del lienzo adosado al terreno, que se puede interpretar como una solución a un problema puntual, el tramo de baluarte parece corresponder a una obra de mayor envergadura, concebida para una defensa global de la Ciudad, en la que se recurre a criterios poliorcéticos específicos.

(El origen de la misma tal vez haya que verlo en la decisión de renovar el sistema defensivo Logroño, tomada tras el sitio de 1521, como precaución ante una posible repetición del episodio, que podía augurarse, a la vista de las tirantes relaciones que existian entre Carlos V y Francisco I) ${ }^{4}$.

En relación con los muros, se llevarían a cabo algunas obras de infraestructura, entre las que se encontrarían los restos de empedrado localizados al pie de la cara externa del

4 F. ALBIA DE CASTRO (1633): "Defensa y victoria grande de la ciudad de Logroño contra el ejército francés que la cercó el año 1521". Memorial y Discurso por la muy noble y muy leal ciudad de Logroño. Lisboa. Folio 101. 
baluarte. Aunque no existen noticias concretas sobre la pavimentación de un posible camino de ronda existente en este sector, hay constancia de la preocupación del Concejo, especialmente en la segunda mitad del siglo XVI, por adecentar algunos parajes contiguos a las murallas.

(Como ejemplo, el 5 de Febrero de 1573 se acuerda empedrar la salida de la Puerta Vieja) $)^{5}$.

En el caso que nos ocupa, el hipotético camino tal vez se relacionase con alguna puerta(la de las Tenerías o de San Pablo) ${ }^{6}$ que daría salida hacia el camino de San Gregorio, , el cuál corría extramuros, paralelo al lienzo sobre el que se apoyaban las casas de la Ruavieja.

Por otra parte, en una sesión del Concejo, celebrada en Febrero de 1590, se planteó la construcción de un abrevadero en la Puerta de las Tenerias ${ }^{7}$. En este sentido, las comprobadas afloraciones del acuífero permitirian abastecer el pilón, pero exigirían realizar obras de acondicionameitno y canalización. Una de ellas bien pudiera haber sido la conducción descubierta al pie del lienzo, en cuya construcción se emplearon ladrillos con un marco habitual a fines del siglo XVI y en el XVII (PLANO N.․ 7).

\section{Reutilizaciones posteriores}

Las modificaciones de las estructuras defensivas debieron ser constantes ya desde antiguo. En este sentido, parece seguro que la construcción de la cárcel, junto a la cabecera de la Iglesia de Santiago, se realizó, al menos parcialmente, cargando sobre el lienzo. Eso se deduce de las noticias que relacionan la ruina de éste con el peligro de destrucción de aquella ${ }^{8}$.

En otro orden de cosas, una vez que la Ciudad perdió el miedo a una nueva invasión, el espacio extramuros comenzó a ser reutilizado para la instalación de talleres artesanales que aprovecharían la fuerza motriz del agua; tanto la obtenida por derivaciones desde el Ebro, como la que desaguaba por la calle de San Pablo, procedente de las capas freáticas y del propio casco urbano.

Estas instalaciones que han permanecido en uso hasta hace escasos lustros, fueron adosándose a los muros defensivos e, incluso, una vez desaparecido el edificio de la antigua cárcel, cubrieron parcialmente la cabecera de la iglesia que Santiago. Es difícil establecer una cronologia por lo que respecta a la reutilización del espacio estudiado.

Una de las primeras adaptaciones sería la que, junto a la construcción de la canalización antes citada, pavimentó el espacio que se extiende al pie del lienzo, utilizando el mismo tipo de ladrillo y losetas de arenisca. Quizá a este momento correspondiesen también los refuerzos de argamasa que se observan en el zócalo del lienzo, con huellas del apoyo de postes que, tal vez sirvieron para sustentar la techumbre.

5 J.M. LOPE TOLEDO (1963): "La limpieza, ornato y segutidad públicas en Logroño en el siglo XVI". Berceo, 67. Logroño. Pág.: 136.

6 R. GOMEZ DE SEGURA (inédito): "Piedras Viejas". Adiciones al Logroño Histórico de F. J. Gómez. Núm. 1308. (Archivo del I.E.R., M/451, pág. 90). Es la primera cita sobre la Puerta de Zurrerías o de San Pablo.

7 J. M. LOPE TOLEDO (1963): Op. cit. Pág. 140.

8 J. M. LOPE TOLEDO (1968): “Logroño en el siglo XVI: La Cárcel Real”. Berceo, 78. Pp.: 23-24. 
Otra modificación, realizada en un momento indeterminado, afectó a la cara exterior del bastión y consistió en la eliminación, a golpe de pico, de cinco hiladas de sillares. La superficie vertical resultante sirvió para apoyar una edificación de la que también se conservan las huellas del apoyo de las vigas.

Por último, los restos de horigón que enmascaran parcialmente las estructuras defensivas, correspoonden, en parte, al refuerzo del lienzo para evitar su desmoronamiento y, en su mayoría, a las cubetas de decantación de un trujal contemporáneo, aunque tal actividad ya se documenta, en este solar, en los planos de mediados del siglo pasado.

CONTRIBUCIÓN DE LA ARQUEOLOGİA AL ESTUDIO DE MONUMENTOS Y CASCOS HISTÓRI$\cos$

A la hora de estudiar conjuntos monumentales de naturaleza religiosa, civil o militar, observamos con demasiada frecuencia el desinterés hacia la investigación arqueológica. Habitualmente estos estudios se fundamentan en referencias documentales, sin profundizar en las tareas de campo y en el análisis del objeto examinado.

La arqueología aporta, sin embargo, una metodología precisa y contrastada que puede ayudar notablemente al conocimiento de importantes aspectos, tanto en la fase de recopilación de información como en la analítica e interpretativa:

-Descubriendo y documentando por completo todos los aspectos de los monumentos, incluso aquellos ocultos al no especializado. Las tareas de limpieza y excavación han de hacerse de acuerdo a pautas muy rigurosas, de forma que exista un estricto control de los datos, evitando la pérdida de algunos de ellos.

-Proporcionando la información necesaria para la perfecta ubicación cronológica de estructuras y monumentos.

-Identificando las alteraciones existentes y sus causas.

-Definiendo las distintas reutilizaciones y modificaciones constatables.

-Enfocando la investigación bibliográfica y documental al definir los aspectos que hay que resolver.

-Completando las lagunas existentes en las fuente escritas. Lagunas que pueden ser intencionadas o bien fruto del desinterés de las mismas hacia datos que ahora juzgamos importantes.

-Datando las diversas fases de utilización.

-Poniendo en relación todos los datos anteriores.

El método arqueológico ofrece también una importante tradición analítica y descriptiva que asegura la fiabilidad de los datos. Sólo se plantea una interpretación cuando cuenta con los criterios suficientes y los ha analizado minuciosamente. Cuando los datos no ofrecen las necesarias garantías la arqueología se manifiesta muy cautelosa, evitando en todo momento la categorización aleatoria.

La restauración de monumentos y la recuperación de los cascos históricos constituyen una oportunidad inestimable para su estudio en profundidad. La actividad arqueológica, que tanto puede aportar en este campo, es sin embargo desatendida por 
los entes responsables de la conservación y recuperación patrimonial.

Se acusa a la arqueologia de obstaculizar los proyectos de remodelación, encarecer los costes y paralizar las obras. Consideramos que estas imputaciones carecen de fundamento y sirven tan sólo como tapadera a la incapacidad organizativa y a la falta de definición cultural de las autoridades competentes. Asistimos por tanto a la constante contradicción entre las formulaciones teóricas sobre Patrimonio y las realizaciones prácticas.

El control arqueológico, como el genéricamente histórico no contribuye a encarecer en modo alguno los planes de remodelación urbanística. Si consideramos el volumen de las inversiones realizadas su alcanze resulta insignificante. El conflicto se produce por deficencias de procedimiento. Partiendo de una organización adecuada podrían delimitarse con tiempo suficiente las prioridades, poniendo en marcha los mecanismos oportunos para planificar con tiempo las actuaciones. Se evitaría así la paralización de obras en curso y las modificaciones a los proyectos iniciales, aspectos realmente costosos. El conocimiento previo de la realidad histórica enriquecería extraordinariamente las propuestas para la recuperaciónde las ciudades.

El caso de la Muralla de Logroño es un buen ejemplo del modelo que debe evitarse. Esperemos que de ahora en adelante se produzca una mejor cocienciación por parte de las autoridades que ayude a evitarlo.

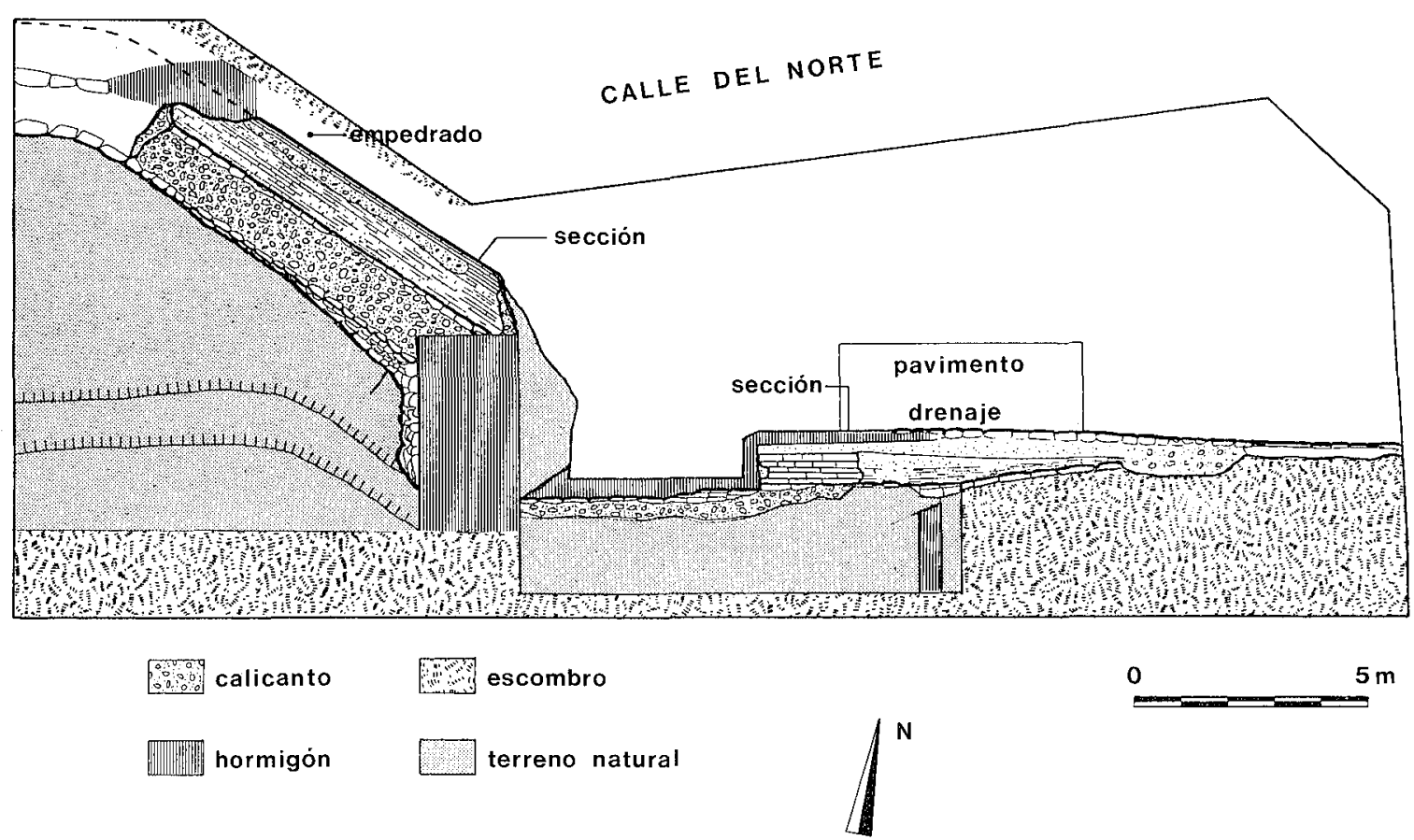


LA MURALLA DE LOGROÑO
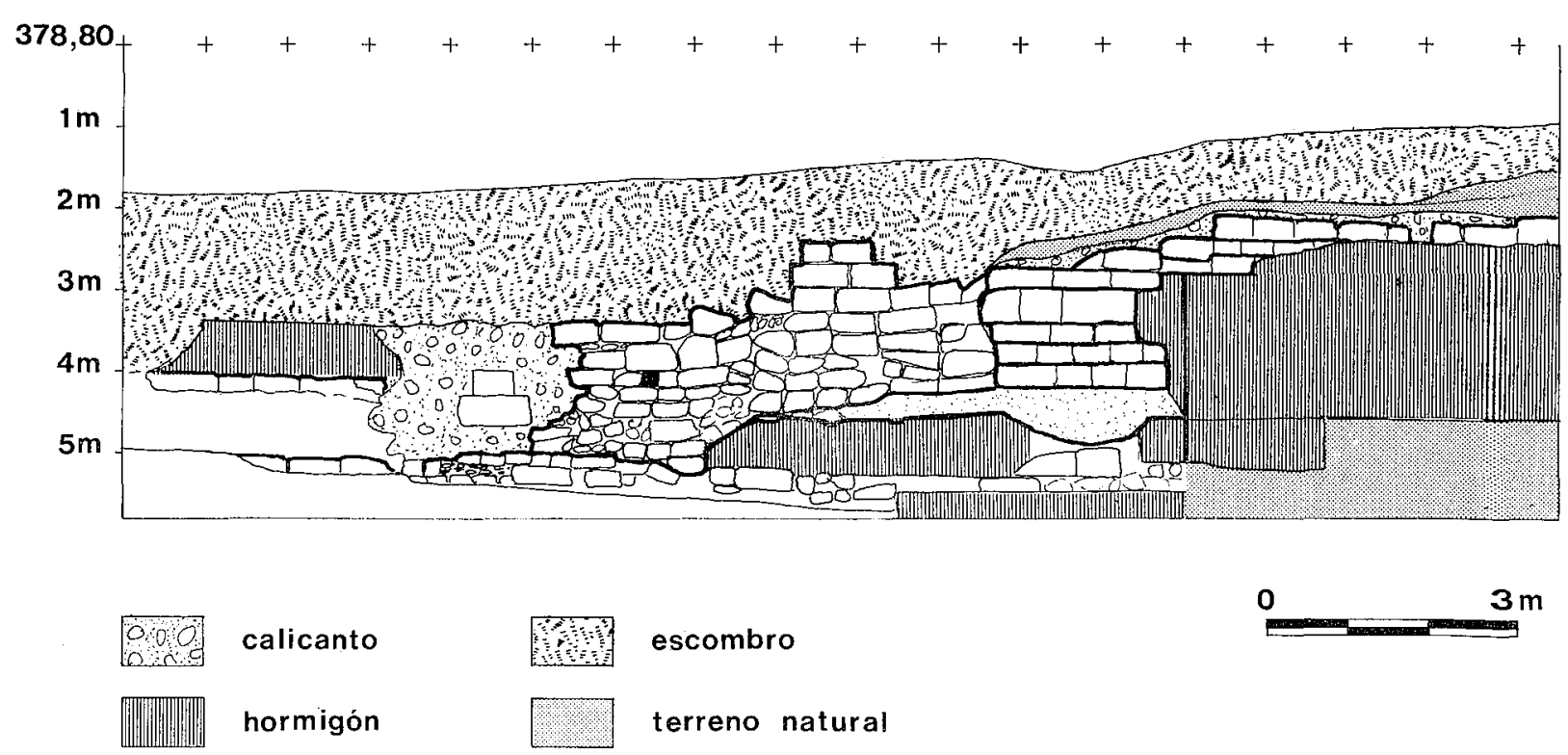

Plano 2. Alzado del lienzo adosado.

378,80

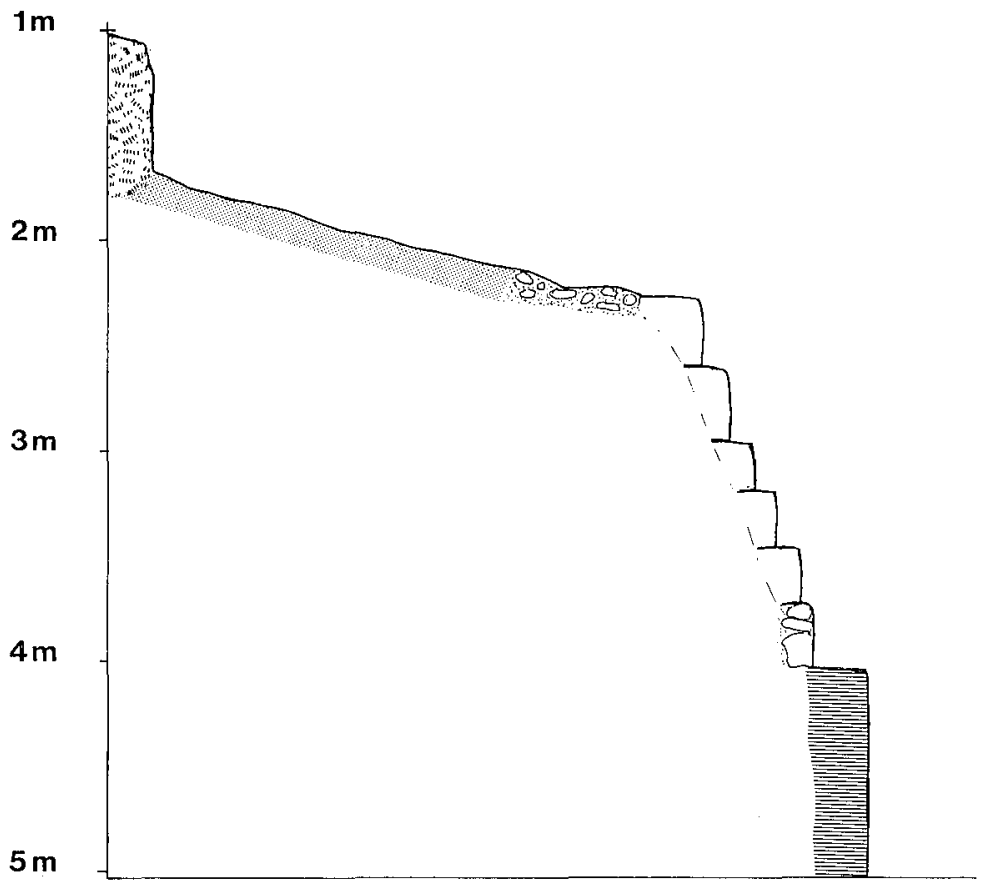

0

\begin{tabular}{lll}
\hline hormigón & escombro \\
80.5 calicanto & terreno natural
\end{tabular}

Plano 3. Sección del contrafuerte del lienzo. 
PEDRO ALVAREZ, JAVIER CENICEROS, JOSE A. TIRADO y JOSE M. TUDANCA

378,80

$1 \mathrm{~m}+$

$2 \mathrm{~m}+$

$3 m+$

$4 \mathrm{~m}+$

$5 \mathrm{~m}+$

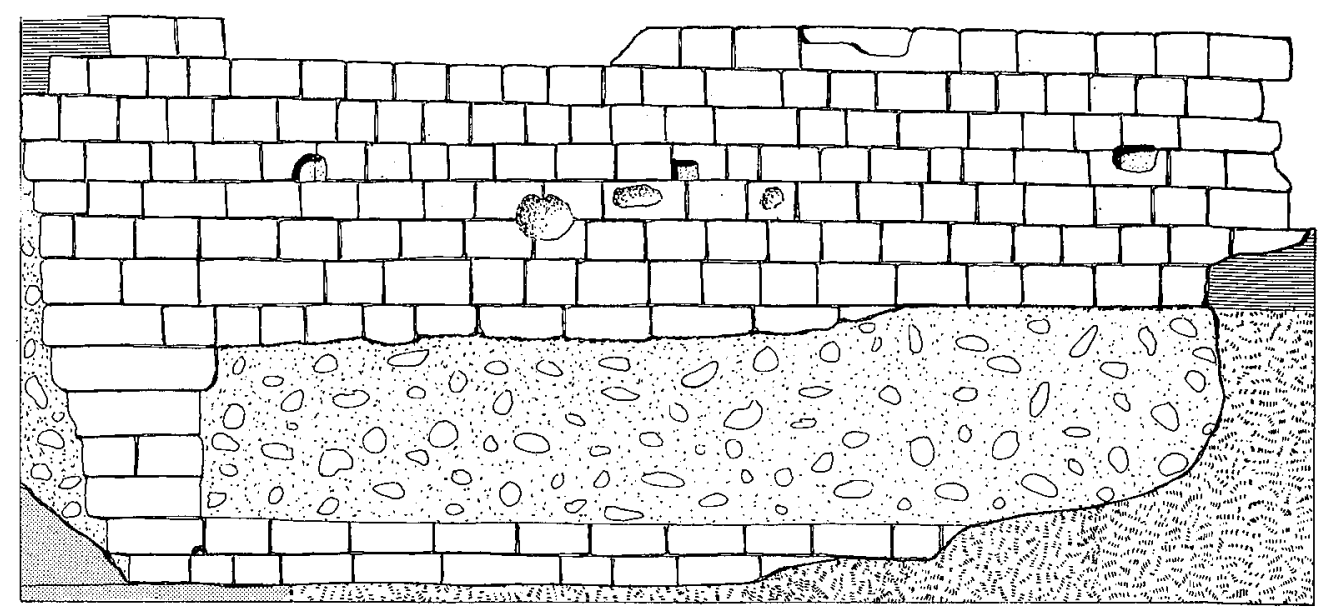

$\begin{array}{lll}00 \% & \text { calicanto } & \text { normigón } \\ \text { escombro } & \text { terreno natura }\end{array}$

Plano 4. Alzado exterior del muro del bastión.

$+378,80+$

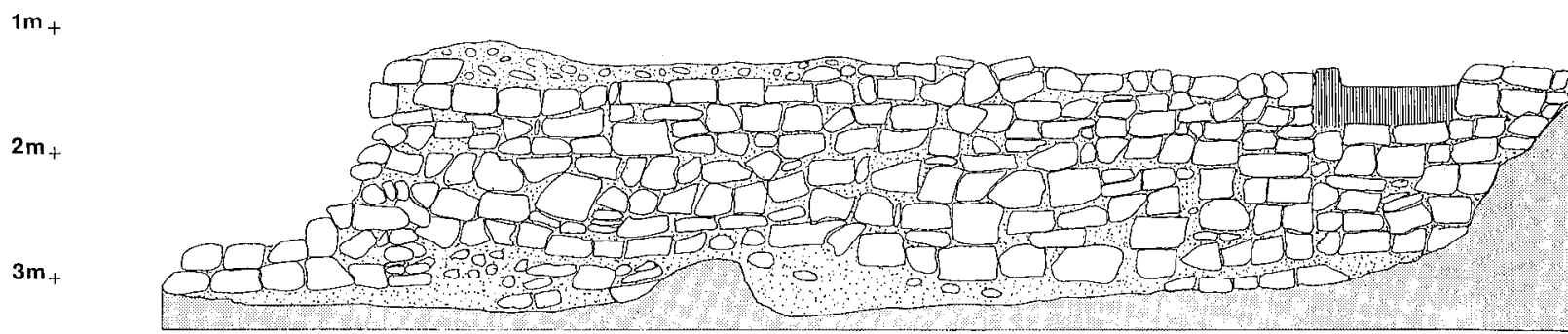

$0 \%$ calicanto

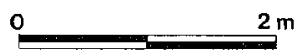

||⿴囗十) hormigón

terreno natural

Plano 5. Alzado interior del muro del bastión. 


\section{LA MURALLA DE LOGROÑO}

$378,80+$

$1 \mathrm{~m}+$
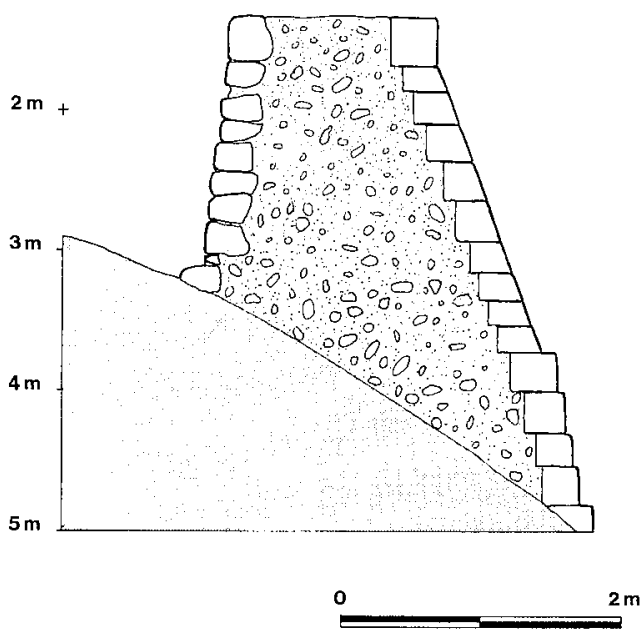

terreno natura

80 calicanto

Plano 6. Sección del muro del bastión

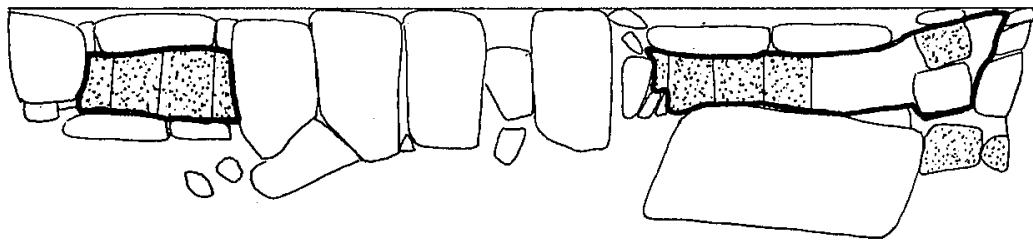

$\Delta$

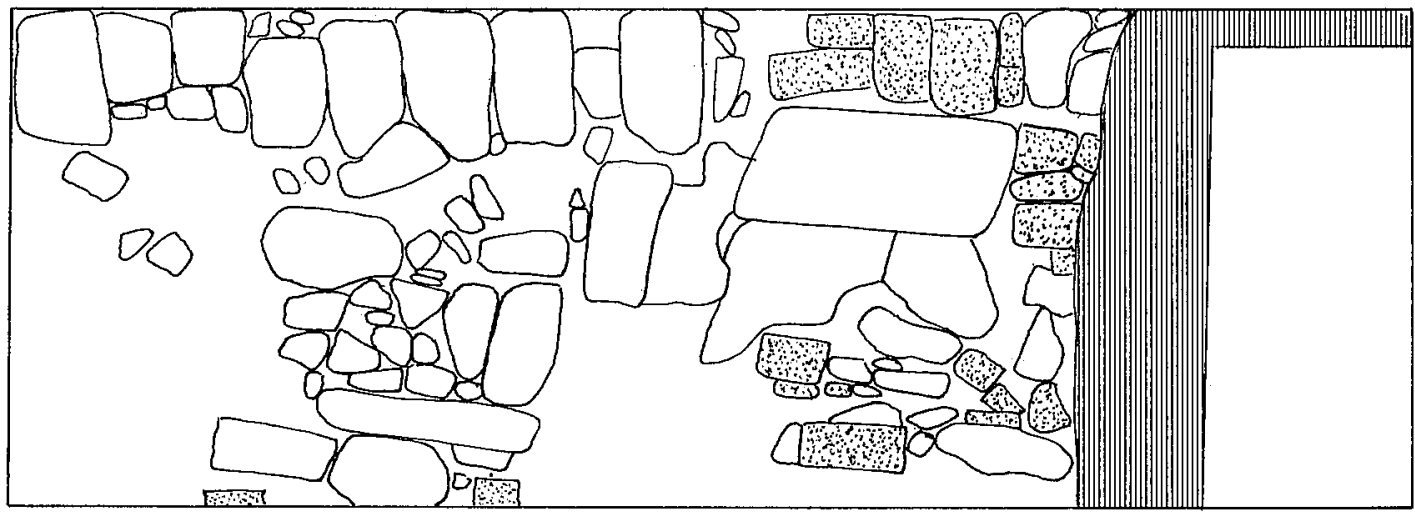

0

ladrillo

hormigón

Plano 7. Pavimento y drenaje del lienzo. 
PEDRO ALVAREZ, JAVIER CENICEROS, JOSE A. TIRADO y JOSE M. TUDANCA

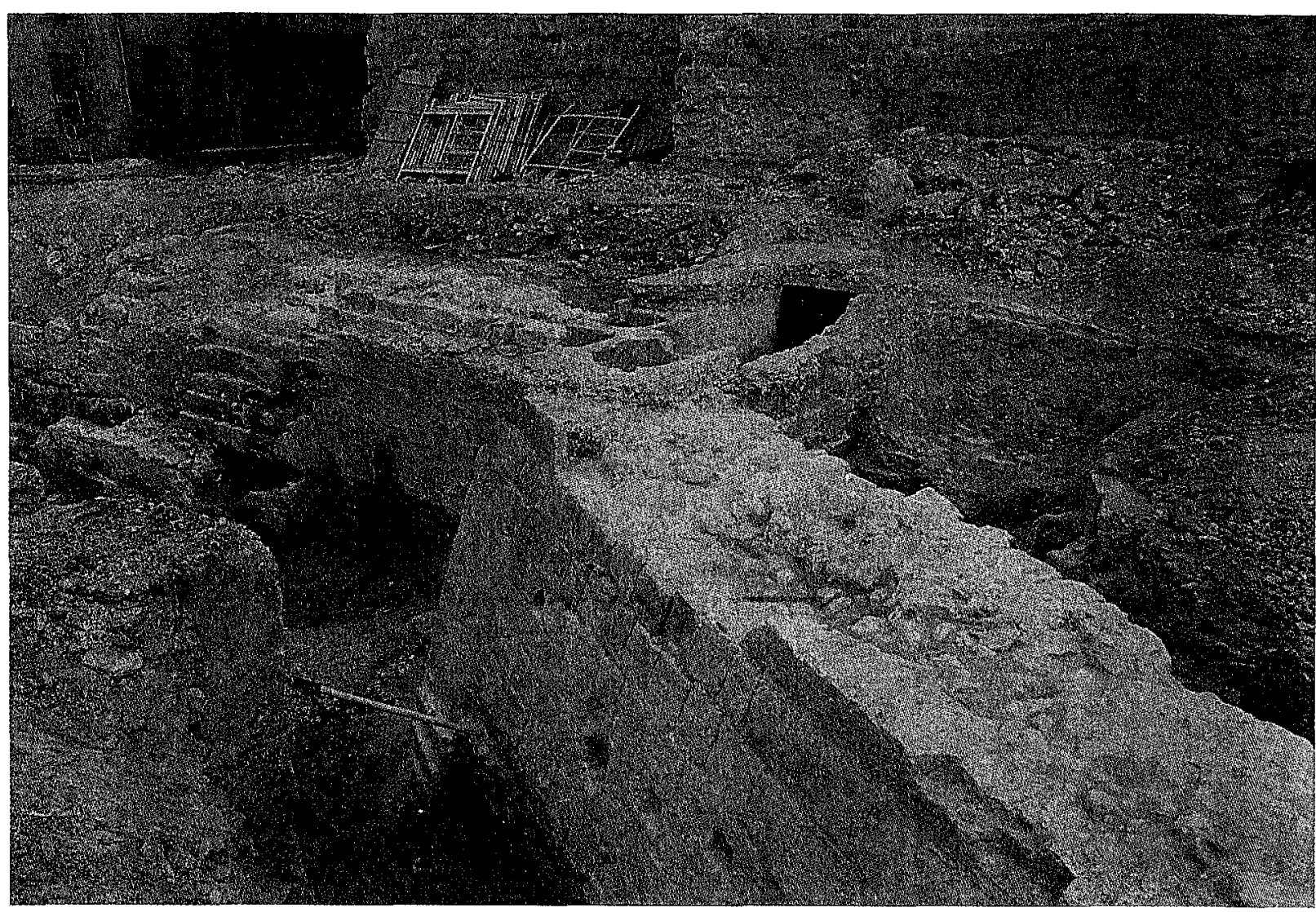

Lám. 1. Vista general de la excavación.

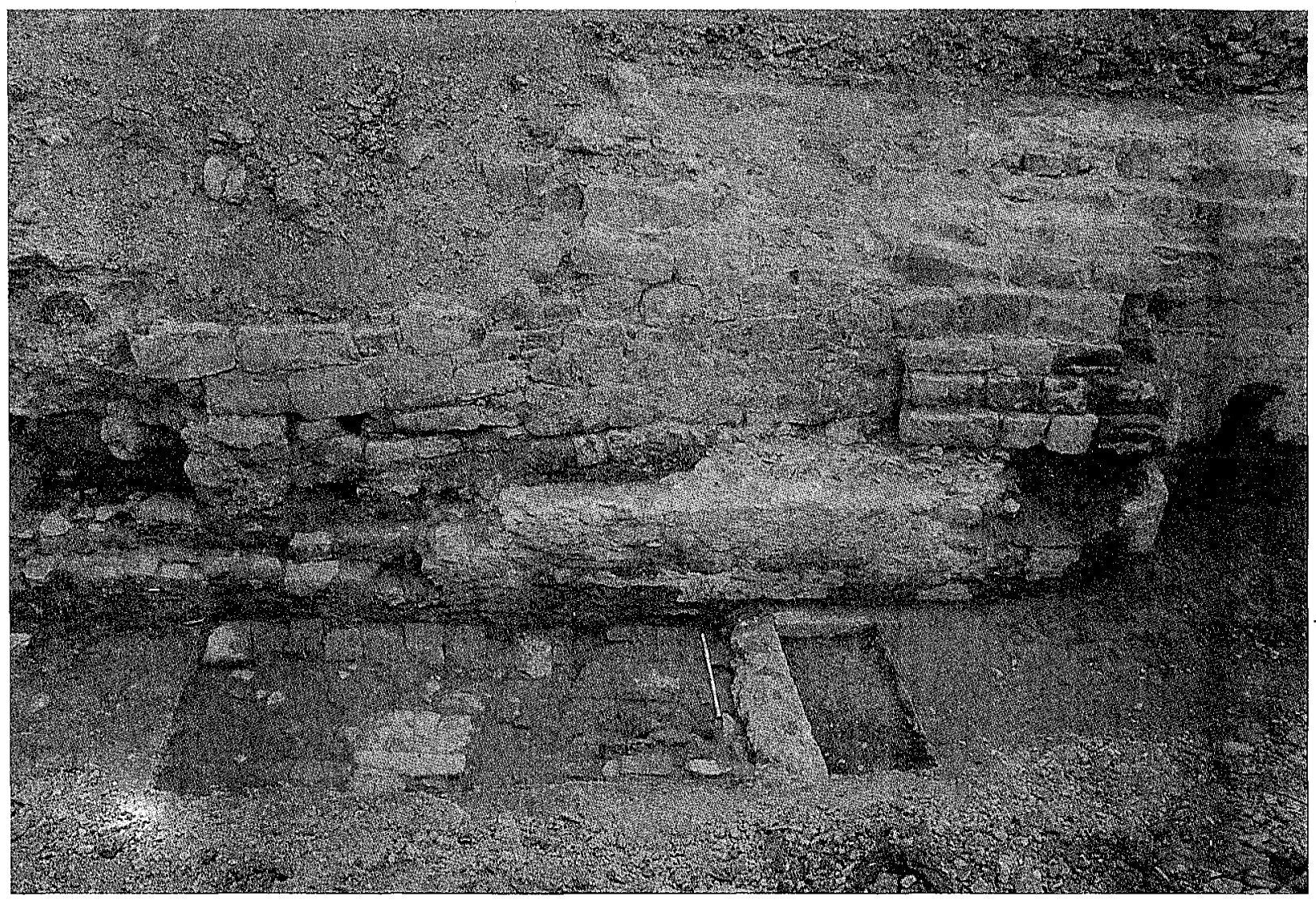

Lám. 2. Lienzo. 


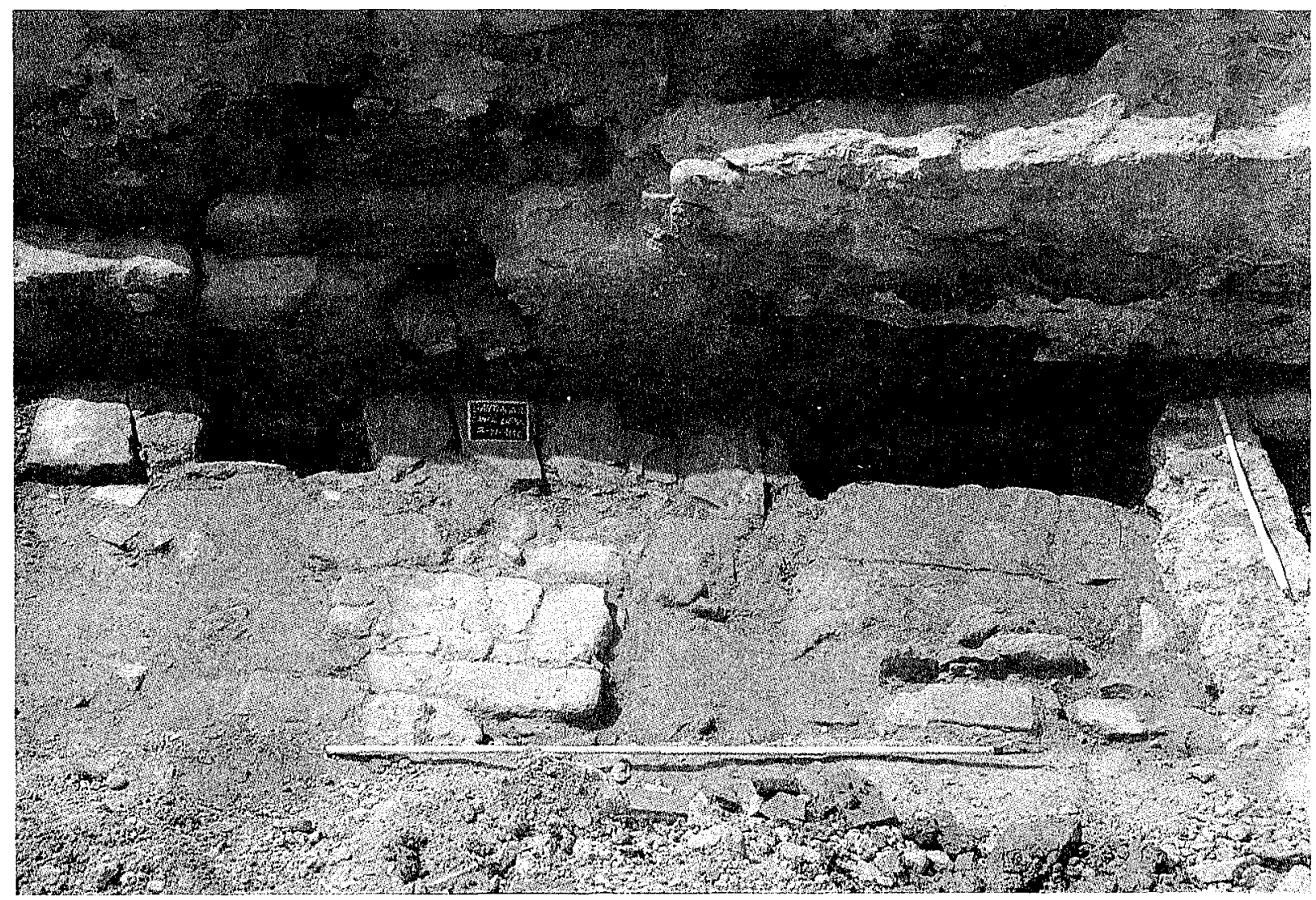

Lám. 3. Canal.

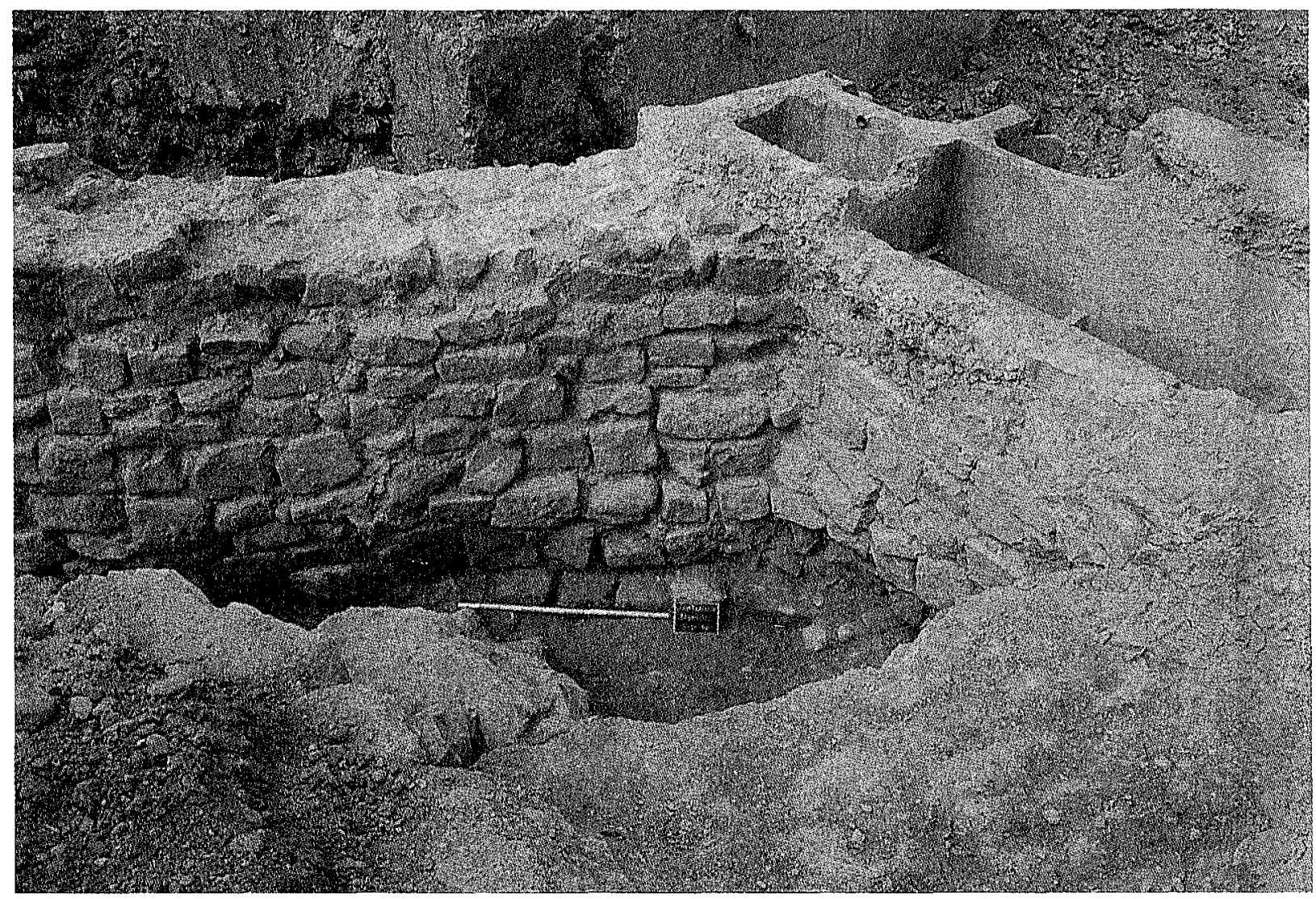

Lám. 4. Interior del baluarte. 
